\title{
Characteristics and robustness of Agulhas leakage estimates: an inter-comparison study of Lagrangian methods
}

\author{
Christina Schmidt $^{1}$, Franziska U. Schwarzkopf ${ }^{1}$, Siren Rühs ${ }^{1}$, and Arne Biastoch ${ }^{1,2}$ \\ ${ }^{1}$ GEOMAR Helmholtz Centre for Ocean Research Kiel, Kiel, Germany \\ ${ }^{2}$ Christian-Albrechts-Universität zu Kiel, Kiel, Germany
}

Correspondence: Arne Biastoch (abiastoch@geomar.de)

Received: 12 April 2021 - Discussion started: 15 April 2021

Revised: 7 July 2021 - Accepted: 10 July 2021 - Published: 16 August 2021

\begin{abstract}
The inflow of relatively warm and salty water from the Indian Ocean into the South Atlantic via Agulhas leakage is important for the global overturning circulation and the global climate. In this study, we analyse the robustness of Agulhas leakage estimates as well as the thermohaline property modifications of Agulhas leakage south of Africa. Lagrangian experiments with both the newly developed tool Parcels and the well established tool Ariane were performed to simulate Agulhas leakage in the eddy-rich ocean-sea-ice model INALT20 $\left(1 / 20^{\circ}\right.$ horizontal resolution) forced by the JRA55-do atmospheric boundary conditions. The average transport, its variability, trend and the transit time from the Agulhas Current to the Cape Basin of Agulhas leakage is simulated comparably with both Lagrangian tools, emphasizing the robustness of our method. Different designs of the Lagrangian experiment alter in particular the total transport of Agulhas leakage by up to $2 \mathrm{~Sv}$, but the variability and trend of the transport are similar across these estimates. During the transit from the Agulhas Current at $32^{\circ} \mathrm{S}$ to the Cape Basin, a cooling and freshening of Agulhas leakage waters occurs especially at the location of the Agulhas Retroflection, resulting in a density increase as the thermal effect dominates. Beyond the strong air-sea exchange around South Africa, Agulhas leakage warms and salinifies the water masses below the thermocline in the South Atlantic.
\end{abstract}

\section{Introduction}

The Agulhas Current system is a key component of the global ocean circulation because it facilitates the exchange of water between the Indian Ocean and the South Atlantic. The Ag- ulhas Current is a strong western boundary current in the Indian Ocean, which flows southwards along the coast of Africa before turning back into the Indian Ocean as the Agulhas Return Current (Lutjeharms, 2006). During this retroflection process, relatively warm and saline water from the Indian Ocean leaks into the South Atlantic by the shedding of large, anticyclonic Agulhas Rings, cyclonic eddies and direct inflow, commonly referred to as Agulhas leakage. Numerical studies indicate that the non-eddy flow contributes around half of the Agulhas leakage transport, whereas Agulhas Rings are less important than previously assumed (Loveday et al., 2015; Cheng et al., 2016). Agulhas leakage supplies the upper limb of the Atlantic Meridional Overturning Circulation (AMOC) with a direct influence on the climate (Weijer et al., 2002; Donners and Drijfhout, 2004; Beal et al., 2011). Modelling studies suggest an increase in Agulhas leakage transport in recent decades (Biastoch et al., 2009; Rouault et al., 2009), but there is still no clear evidence of a long-term trend in Agulhas leakage from observations (Backeberg et al., 2012; Le Bars et al., 2014). An increase in Agulhas leakage can be related to changes in Southern Hemisphere westerlies, especially their strengthening, under global warming (Durgadoo et al., 2013; Biastoch and Böning, 2013; Biastoch et al., 2015; Cheng et al., 2018). A sensitivity study using an idealized Lagrangian analysis set-up with a realistic eddy-rich ocean-sea-ice model shows that such an increase in Agulhas leakage also increases the contribution of waters entering the South Atlantic from the Indian Ocean to the upper limb of the AMOC, while the contribution entering from the Pacific through Drake Passage decreases (Rühs et al., 2019). 
The region south of Africa where the interbasin exchange occurs also is a region of vigorous thermohaline property modifications of Agulhas leakage waters by air-sea fluxes and mixing with other water masses (Boebel et al., 2003). Both mesoscale and submesoscale dynamics affect the thermohaline structure of upper and intermediate waters locally with different dynamical regimes in the vertical (Capuano et al., 2018). During the advection of Agulhas leakage waters into the South Atlantic, the relatively warm upper water masses undergo cooling due to strong heat loss (Walker and Mey, 1988). The intermediate water of Agulhas leakage, Antarctic Intermediate Water (AAIW) from the Indian Ocean (I-AAIW), experiences mixing with the fresher AAIW of the South Atlantic (A-AAIW) in the Cape Basin to form the new Indo-Atlantic AAIW variety (Rusciano et al., 2012). Most of the studies on the evolution of thermohaline properties have, however, focused on a particular Agulhas Ring (e.g. Schmid et al., 2003) or specific region like the Cape Basin (Rimaud et al., 2012; Rusciano et al., 2012). One aim of this study is to evaluate the modifications of the thermohaline properties of Agulhas leakage during the transit from the Agulhas Current into the Cape Basin (see Fig. $4 \mathrm{c}$ for the location of the Cape Basin) and to identify the dominant effect on density associated with these modifications.

Several methods exist to estimate the Agulhas leakage transport both in the real ocean and using numerical models. First estimates were only built on the observations of Agulhas Rings using satellite data and in situ measurements based on the assumption that Agulhas Rings carry the majority of Agulhas leakage (de Ruijter et al., 1999). Using subsurface floats and surface drifters, a mean Agulhas leakage transport including all varieties in which leakage can occur was estimated to be $15 \mathrm{~Sv}\left(1 \mathrm{~Sv}:=10^{6} \mathrm{~m}^{3} \mathrm{~s}^{-1}\right)$ in the upper $1000 \mathrm{~m}$ (Richardson, 2007) and $21.3 \pm 4.7 \mathrm{~Sv}$ in the upper $2000 \mathrm{~m}$ (Daher et al., 2020). Furthermore, a time series of the anomalies of Agulhas leakage transport was derived using satellite altimetry (Le Bars et al., 2014). It is not possible to determine the Agulhas leakage transport precisely from Eulerian velocity fields, even in ocean models where threedimensional velocity fields over time exist, since those also include the imprint of other circulation systems in the greater Agulhas region, such as for example the subtropical gyre in the South Atlantic (van Sebille et al., 2010). As a result, a Lagrangian approach or tracer-based estimates in ocean models are used to analyse the variability, trends and characteristics of Agulhas leakage in more detail. For the tracer-based estimate, either an additional passive tracer labelling Indian Ocean water masses is introduced (Loveday et al., 2015) or a passive tracer is calculated based on thermohaline properties (Putrasahan et al., 2015). The tracking of particles with offline Lagrangian tools is the most widely used approach to estimate Agulhas leakage in ocean models due to its flexibility (e.g. Doglioli et al., 2006; Biastoch et al., 2008; van Sebille et al., 2009). This kind of Lagrangian leakage estimation always consists of releasing virtual fluid particles in the Agulhas Current representing a certain portion of the original transport, following their pathways within the simulated flow, and finally sampling those particles that enter and remain in the South Atlantic and hence sum up to Agulhas leakage. However, the employed Lagrangian tools and the specific design of the Lagrangian experiments vary among studies. To assess the robustness of Lagrangian leakage estimates with respect to these differences is another aim of this study.

Most commonly, the Lagrangian tools Ariane (Blanke and Raynaud, 1997; Blanke et al., 1999) and the Connectivity Modeling System (CMS; Paris et al., 2013) are used to estimate Agulhas leakage. Ariane, because of its close correspondence to the numerical grids of NEMO (Madec and the NEMO Team, 2014) and ROMS (Shchepetkin and McWilliams, 2003), was used for example by Speich et al. (2006), Doglioli et al. (2006), Biastoch et al. (2008) and Durgadoo et al. (2013), and CMS was used for example by Weijer and van Sebille (2014), Biastoch et al. (2015), Cheng et al. (2018) and Daher et al. (2020). The transport of Agulhas leakage was only calculated once with the newly developed tool Parcels (Lange and Sebille, 2017; Delandmeter and van Sebille, 2019) and then compared to an estimate using CMS where an overly strong diffusion of the velocity fields due to the interpolation method in CMS was suspected and therefore Parcels was preferred (Daher et al., 2020). In this study, we validate the Agulhas leakage estimates by Parcels against the results from Ariane, as Parcels is a more flexible Lagrangian tool, for example with respect to the layout of velocity field discretization, and can be used for a variety of studies on Agulhas leakage dynamics in the future.

In addition, the design of the Lagrangian experiments varies in terms of the release and sampling sections, number of crossings of the control section and the date that the Agulhas leakage transport is assigned to. Lagrangian particles are released in the Agulhas Current either at $32^{\circ} \mathrm{S}$ or along the section of the Agulhas Current Time-series Experiment (ACT; Beal et al., 2015) at $34^{\circ} \mathrm{S}$, which alters the mean Agulhas leakage transport but does not affect its variability strongly (Cheng et al., 2016). In all studies, particles crossing an approximation of the Good Hope section (Ansorge et al., 2005) are referred to as Agulhas leakage. Although the Good Hope section is defined differently, it always lies west of the Agulhas Retroflection and cuts through the Cape Basin. Thereby, a crossing should ensure that waters with an Indian Ocean origin remain in the South Atlantic. Due to the turbulent dynamics in the Cape Basin, the Good Hope section might be crossed several times if a particle is trapped inside an eddy. An odd number of crossings can therefore be required to guarantee that the Lagrangian particles remain in the Atlantic (Cheng et al., 2016; Daher et al., 2020). A detailed comparison of the different parameters of the Lagrangian experiment is needed within the same ocean model to examine their effect on the resulting estimate of Agulhas leakage independent of the underlying circulation. 
In this study, we estimate the transport and analyse the water mass characteristics of Agulhas leakage in an eddy-rich ocean-sea-ice model $\left(1 / 20^{\circ}\right.$ horizontal resolution) with two Lagrangian tools. First, we validate the simulated Agulhas leakage by the newly developed tool Parcels against the results by the well established tool Ariane and investigate the impact of different designs of the Lagrangian experiment in Sect. 3.1-3.3. In Sect. 3.4, the water mass characteristics of Agulhas leakage and their modifications south of Africa are analysed.

\section{Materials and methods}

\subsection{Ocean model simulation}

Output from a hindcast simulation with the eddy-rich oceansea-ice model configuration INALT20 (Schwarzkopf et al., 2019) from 1958 to 2018 was used to conduct offline Lagrangian experiments. INALT20 is based on the ocean general circulation model NEMO (version 3.6; Madec and the NEMO Team, 2014) coupled to the Louvain-La-Neuve sea ice model version 2 (LIM-V2; Fichefet and Maqueda, 1997). A tripolar Arakawa $\mathrm{C}$ grid with a horizontal resolution of $1 / 4^{\circ}$ is used for the global host in which a nest with a horizontal resolution of $1 / 20^{\circ}$ between $63^{\circ} \mathrm{S}-10^{\circ} \mathrm{N}$ and $70^{\circ} \mathrm{W}-$ $70^{\circ} \mathrm{E}$ is embedded via two-way nesting using AGRIF (Adaptive Grid Refinement in Fortran; Debreu et al., 2008). In the vertical, INALT20 consists of $46 z$ levels with a layer thickness of $6 \mathrm{~m}$ near the surface increasing to $250 \mathrm{~m}$ in the deepest layers. Cells at the bottom are allowed to be partially filled for a better representation of the bathymetry.

The hindcast simulation used here mainly differs from the experiment described and evaluated by Schwarzkopf et al. (2019) in the applied surface forcing. Here, atmospheric boundary conditions are given by the JRA55-do forcing data set covering the period from 1958 to the present (Tsujino et al., 2018). The main difference in this forcing set, compared to the previously applied COREv2 data set (Coordinated Ocean-Ice Reference Experiments data set version 2; Large and Yeager, 2009) is an increased horizontal (from 2 to $0.5^{\circ}$ ) and temporal (from 6 hourly, daily and monthly, depending on the forcing variable, to 3 hourly) resolution as well as the extension throughout the 2010s. Additionally, river runoff, which has previously been prescribed as a climatological field, is now interannually varying at daily resolution. Furthermore, 11 of the major tidal components are simulated here, while the experiment presented by Schwarzkopf et al. (2019) was non-tidal. All other parameters, including the preceding spin-up, are identical to their experiment "INALT20 NS_RW". Although there are differences between these simulations, the large-scale horizontal circulation and also the representation of mesoscale variability in the area of interest to the present study are qualitatively comparable.

\subsection{Lagrangian experiments}

For the comparison of the two Lagrangian methods, Ariane and Parcels, different sets of Lagrangian experiments (Table 1) were conducted, and the mean transport, interannual variability and trend from 1958 to 2014 of Agulhas leakage were analysed. In these experiments, particles were released in the Agulhas Current, and all particles crossing the approximated Good Hope section in the Cape Basin were referred to as Agulhas leakage (Fig. 1a). To advect the particles, the three-dimensional $5 \mathrm{~d}$ mean velocity fields from INALT20 were used. This temporal resolution of the velocity fields is sufficient for these offline Lagrangian experiments as flow characteristics of the Agulhas Current system do not change significantly when using up to $9 \mathrm{~d}$ mean velocity fields (Qin et al., 2014).

In Ariane (Blanke and Raynaud, 1997; Blanke et al., 1999), virtual particles are advected along analytically computed streamlines, which are calculated from the threedimensional, non-divergent velocity field on an Arakawa C grid for each output time period. The velocities are linearly interpolated in space, while they are assumed to be constant in time for the given output frequency of the model simulation. The interpolation and integration methods employed by Ariane respect the local non-divergence of the input files and the resulting trajectories represent volume transport pathways, which may experience along-track tracer and density changes that reflect the sub-grid-scale parametrization of the underlying ocean model. In our Lagrangian experiment with Ariane (version 2.3.0_02), which is hereafter referred to as experiment $\mathrm{A}$, particles with an initial maximum transport of $0.1 \mathrm{~Sv}$ were released automatically and continuously according to the transport in the Agulhas Current at $32^{\circ} \mathrm{S}$ over 1 year. All trajectories were integrated forward in time over the same length of 4 years after initialization, so that the total experiment length is 5 years. The transport assigned to a particle takes the reduced volume of partially filled cells at the bottom into account. The built-in seeding strategy in the quantitative mode of Ariane is as follows: in grid cells with a transport smaller than the maximum transport per particle, one particle per grid cell is seeded on the $v$ point at the centre of the $5 \mathrm{~d}$ mean model output fields (Fig. 1b). If the transport through a grid cell is greater than the maximum transport per particle, eight particles are released, with four of them at the first quarter of the temporally averaged model output and four particles after the third quarter. In our case, the former related to a release at 06:00 UTC the day before the centre of the $5 \mathrm{~d}$ mean output and the latter to a release at 18:00 UTC the day after the centre of the $5 \mathrm{~d}$ mean output. Such a group of four particles was regularly seeded in the $x-z$ plane centred around the $v$ point. In partially filled cells at the bottom, particles were also released in the middle of the cell in the vertical and hence above particles at the same depth level in fully filled cells. A total of 57 of these 1 -year release experiments with on average 186000 particles 
Table 1. Parameters of the Lagrangian experiments.

\begin{tabular}{|c|c|c|c|}
\hline Lagrangian experiment & A & $\mathrm{P}$ & P-ACT \\
\hline Lagrangian tool & Ariane & \multicolumn{2}{|c|}{ Parcels } \\
\hline Advection method & analytic & \multicolumn{2}{|c|}{ fourth-order Runge-Kutta } \\
\hline Release section & \multicolumn{2}{|l|}{$32^{\circ} \mathrm{S}$} & $\mathrm{ACT}$ at $34^{\circ} \mathrm{S}$ \\
\hline Release positions & regularly & \multicolumn{2}{|c|}{ randomly } \\
\hline Release frequency & $3 \times$ every $5 \mathrm{~d}$ over 1 year & \multicolumn{2}{|c|}{ once every $5 \mathrm{~d}$ over 1 year } \\
\hline Release period & \multicolumn{3}{|c|}{$1958-2014$} \\
\hline Advection time & \multicolumn{3}{|c|}{4 years } \\
\hline Particles released on average per year & ca. 186000 & ca. 110000 & ca. 176000 \\
\hline
\end{tabular}

per year were conducted for the years 1958-2014. As the experiments were run in the so called "quantitative" mode, the position, time and transport of a particle were only stored at its release as well as when the particle crossed a predefined section for the first time. All particles not leaving the domain enclosed by these sections within the integration time were considered as "lost".

In Parcels (Lange and Sebille, 2017; Delandmeter and van Sebille, 2019), virtual particles are advected numerically with different schemes and customizable advection methods being available. If the velocity and tracer fields are discretized on a $\mathrm{C}$ grid, the velocity fields are linearly interpolated in space and time, while the tracer fields are linearly interpolated in time, but constant over a grid cell. In our first Lagrangian experiment with Parcels (hereafter referred to as experiment $\mathrm{P}$ ), particles were three-dimensionally advected forward in time using the fourth-order Runge-Kutta scheme with Parcels version 2.2.0. Although this integration scheme is not necessarily volume conserving, it has been used to estimate volume transport pathways (van Sebille et al., 2012, 2014) since without diffusion trajectories calculated with the fourth-order Runge-Kutta scheme and an appropriate time step are very similar to trajectories of the analytical, volume-conserving method (van Sebille et al., 2018). When using the fourth-order Runge-Kutta scheme, the time step $\mathrm{d} t$ should be small enough that particles do not skip grid cells and thereby miss characteristic oceanographic features. After considering the trade-off between the accuracy of the time stepping and the computation time of the experiment, the time step $\mathrm{d} t$ was chosen such that particles stay in one model grid cell for at least 2 time steps. Therefore, a time step $\mathrm{d} t$ of 16 min was calculated following $\mathrm{d} t<\mathrm{d} s_{\min } /\left(v_{\max } \cdot 2\right)$ where $\mathrm{d} s_{\min }$ is the smallest edge of all grid cells in the domain and $v_{\max }$ is the largest horizontal velocity. The time step should also not be smaller than necessary to avoid the accumulation of round-off errors. Similarly to experiment A, particles were released in the Agulhas Current at $32^{\circ} \mathrm{S}$ over 1 year for the years $1958-2014$ and then advected for 4 years. Thereby, potential temperature $\theta$ and practical salinity $S$ were sampled and together with the position of the particles stored daily. The number of particles seeded and their position was determined based on the transport of the Agulhas Current at $32^{\circ} \mathrm{S}$. Therefore, the southward transport per grid cell at $32^{\circ} \mathrm{S}$ over the whole water column was calculated for each time step of the model output, i.e. every $5 \mathrm{~d}$, and the number of particles per grid cell and their individual transport identified accordingly such that the maximum transport per particle was $0.1 \mathrm{~Sv}$. If the transport through a grid cell was $0.24 \mathrm{~Sv}$ for example, which can occur in the core of the Agulhas Current, three particles were released in that grid cell with each of them having a transport of $0.24 \mathrm{~Sv} / 3=0.08 \mathrm{~Sv}$. The calculated number of particles was seeded randomly in the $x$ and $z$ directions in each grid cell every $5 \mathrm{~d}$ (Fig. 1c) resulting in 110000 particles being released on average each year. Although partially filled bottom cells are not implemented in Parcels, they were considered when computing the transport of the particles. While the release of the particles in both experiments $\mathrm{A}$ and $\mathrm{P}$ are based on the same transport of the Agulhas Current at $32^{\circ} \mathrm{S}$, the number of particles and their individual transport as well as their release position and release time differ between $\mathrm{A}$ and $\mathrm{P}$. The computational cost of those experiments is also different with the runtime of experiment $P$ being about 7 times longer than for $\mathrm{A}$, but there is potential to increase the model efficiency in Parcels with the aim of a fully parallel version (Delandmeter and van Sebille, 2019). The section crossed by a particle was calculated in a second step such that only the first section crossed by a particle leaving the domain was considered for later analysis.

For the comparison of the effect of different designs of the experiment, in particularly the release section, on the Agulhas leakage transport, a second experiment was performed with Parcels (hereafter referred to as P-ACT). In P-ACT, the particles were released along the ACT section at $34^{\circ} \mathrm{S}$ in the Agulhas Current (Fig. 1a). The section "East", used to define the transport of the Agulhas Return Current, was thereby 


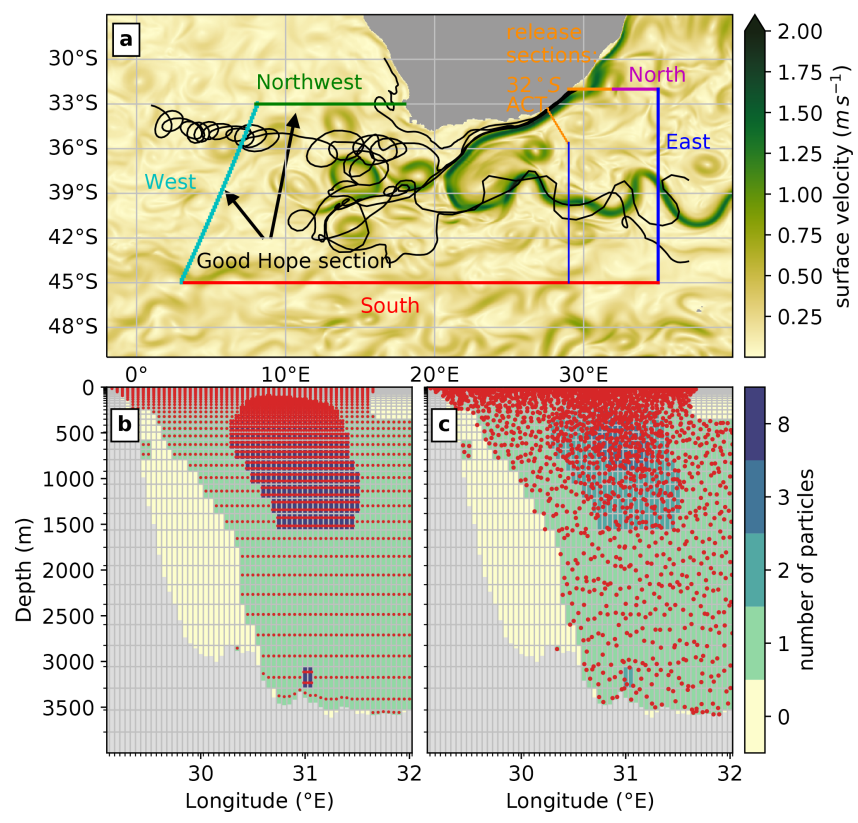

Figure 1. Design of the Lagrangian experiments A, P and P-ACT: (a) release section $32^{\circ} \mathrm{S}$ for $\mathrm{A}$ and $\mathrm{P}$ and release section ACT for $\mathrm{P}$-ACT in orange and all sampling sections as thick lines for $\mathrm{A}$ and $\mathrm{P}$ and as thin lines for P-ACT if differing from A and P. Exemplary trajectories of experiment $\mathrm{P}$ are shown as black lines as well as a snapshot of the surface velocity on 3 January 2010 as simulated in INALT20. Note that the sections "West" and "Northwest" are only an approximation of the locations of the observations at the Good Hope section. Release positions of particles (shown as red dots) in experiment (b) A and (c) $\mathrm{P}$ with a shading of the number of particles per grid cell. These particles were released at 12:00 UTC on 3 January 2010 in experiment $\mathrm{P}$ and in experiment A if only 1 particle was released per grid cell. If eight particles were released per grid cell in experiment $\mathrm{A}$, four of them were released at 06:00 UTC on 2 January 2010 and the other four at 18:00 UTC on 4 January 2010 from the same positions. In (b) and (c) the grid lines show the model grid and the grey shading the bathymetry with its partially filled grid cells at the bottom.

shifted westwards to $29^{\circ}$ E. Otherwise, experiment P-ACT was conducted in exactly the same way as experiment $P$.

In all experiments, the transport across the defined sections was calculated by summing up the transport of all particles crossing the respective section and dividing by the number of release times per year. Only the section crossed first was considered here as this is automatically done in experiment A. The Agulhas leakage transport is given by the sum of the transport of all particles crossing the sections "West" and "Northwest", which approximate the Good Hope section.

\subsection{Modifications of thermohaline properties}

The modifications of the thermohaline properties of Agulhas leakage can be evaluated in terms of a horizontal distribution of the density changes $\mathrm{d} \rho$. $\frac{\mathrm{d} \rho}{\mathrm{d} t}=-\alpha(\bar{S}, \bar{\theta}, \bar{p}) \frac{\mathrm{d} \theta}{\mathrm{d} t}+\beta(\bar{S}, \bar{\theta}, \bar{p}) \frac{\mathrm{d} S}{\mathrm{~d} t}+\kappa(\bar{S}, \bar{\theta}, \bar{p}) \frac{\mathrm{d} p}{\mathrm{~d} t}$,

where the overbar denotes a time average as follows:

$\bar{X}=\frac{X_{t}+X_{t+1}}{2}$,

$\alpha$ is the thermal expansion coefficient, $\beta$ the saline contraction coefficient, $\kappa$ the isentropic compressibility and $p$ pressure. As we were only interested in the density changes due to the thermal and the haline effect, only the first and second term in Eq. (1) were computed. First, the changes in density per day due to the thermal effect (Eq. 3) and the haline effect (Eq. 4) were calculated for each Lagrangian particle $P$ along its trajectory. In a second step, the particles' positions were binned into spatial histograms whereby the unit weight of each particle is based on the product of its transport $T$ and the density changes per day along the part of the trajectory passing through a certain bin. In other words, all particles passing a certain geographical bin along their way were selected, and their density changes per day along the part of the trajectory passing through this bin, weighted by the individual particle's transport, were summed up. Finally, this was divided by the total Agulhas leakage transport as represented by all particles passing through the region. Note that particles remaining in a bin longer than a day or crossing a bin several times were also repeatedly captured in the summation of the density changes as well as transports.

$\frac{\mathrm{d} \rho_{\theta}}{\mathrm{d} t}=$

$\frac{\sum_{j=\operatorname{lat}_{\min }}^{\text {lat }_{\max }} \sum_{i=\operatorname{lon}_{\min }}^{\operatorname{lon}_{\max }} \sum_{\mathrm{P}}-\alpha_{\mathrm{P}} \frac{\mathrm{d} \theta_{\mathrm{P}}}{\mathrm{d} t} T_{\mathrm{P}} \mathbb{1}\left\{x_{\mathrm{P}} \in[i, i+\Delta x)\right\} \mathbb{1}\left\{y_{\mathrm{P}} \in[j, j+\Delta y)\right\}}{\sum_{\mathrm{P}} T_{\mathrm{P}} \mathbb{1}\left\{x_{\mathrm{P}} \in \mathbb{Q}\right\}}$,

$\frac{\mathrm{d} \rho_{S}}{\mathrm{~d} t}=$

$\frac{\sum_{j=\text { lat }_{\min } i=\operatorname{lon}_{\min } \mathrm{P}}^{\text {lat }_{\max }} \sum_{\mathrm{P}} \beta_{\mathrm{P}} \frac{\mathrm{d} S_{\mathrm{P}}}{\mathrm{d} t} T_{\mathrm{P}} \mathbb{1}\left\{x_{\mathrm{P}} \in[i, i+\Delta x)\right\} \mathbb{1}\left\{y_{\mathrm{P}} \in[j, j+\Delta y)\right\}}{\sum_{\mathrm{P}} T_{\mathrm{P}} \mathbb{1}\left\{x_{\mathrm{P}} \in \mathbb{Q}\right\}}$,

where $\mathbb{1}_{\mathrm{A}}(x)$ is the indicator function.

$\mathbb{1}_{\mathrm{A}}(x):= \begin{cases}1 & \text { if } x \in A \\ 0 & \text { if } x \notin A\end{cases}$

The bin size is $\Delta y=2^{\circ}$ in latitude $\times \Delta x=3^{\circ}$ in longitude, which is larger than the maximum distance travelled per day by a particle of $206 \mathrm{~km}$ to avoid aliasing.

\section{Results}

\subsection{Agulhas leakage transport}

The mean (1958-2014) Lagrangian transport across all defined sections and its variability with respect to the release 


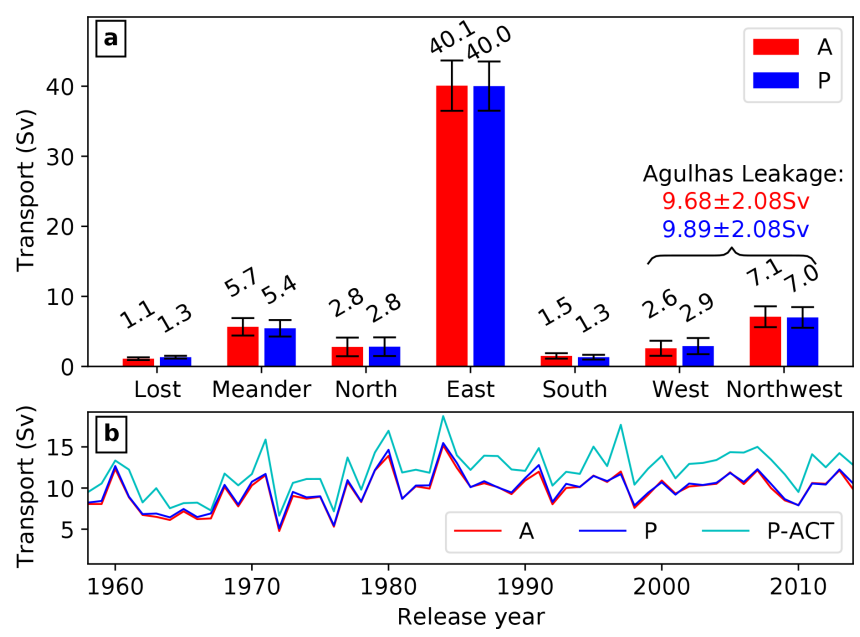

Figure 2. (a) Mean (1958-2014) transport across all sections as shown in Fig. 1 for experiment $\mathrm{A}$ in red and $\mathrm{P}$ in blue. The transport of all particles not crossing any section is shown as "Lost" and the transport of all particles leaving the region by crossing the release section again is shown as "Meander". (b) Time series of the Agulhas leakage transport for A (red), P (blue) and P-ACT (cyan).

year agree well for experiments A and P (Fig. 2), despite the two different Lagrangian tools Ariane and Parcels being used and the resulting differences in advection schemes, interpolation and release strategy. In both A and P, the majority of the Agulhas Current transport at $32^{\circ} \mathrm{S}$ reflects back into the Indian Ocean and constitutes the Agulhas Return Current, thereby crossing the section "East" with a mean transport of 40.1 Sv in experiment A and 40.0 Sv in P. Particles with a combined transport of approximately $1 \mathrm{~Sv}$, accounting for $2 \%$ of the overall transport, do not leave the area within 4 years in both A and P. The Agulhas leakage transport for the years 1958 to 2014 is on average $9.7 \mathrm{~Sv}$ in experiment $\mathrm{A}$ and 9.9 Sv in $\mathrm{P}$ with a similar standard deviation in both experiments of $2.1 \mathrm{~Sv}$. In general, we found a good agreement of the simulated transport across all sections in $\mathrm{A}$ and $\mathrm{P}$ with its differences between $\mathrm{A}$ and $\mathrm{P}$ being smaller than the standard deviation due to interannual variability. The simulated Agulhas leakage transport is, however, considerably lower than the estimate of mean Agulhas leakage from floats and drifters of at least $15 \mathrm{~Sv}$ in the upper $1000 \mathrm{~m}$ (Richardson, 2007) and $21.3 \pm 4.7 \mathrm{~Sv}$ in the upper $2000 \mathrm{~m}$ (Daher et al., 2020). These observed transports of Agulhas leakage were obtained by weighting the ratio of leaking floats and drifters by the transport of the Agulhas Current at $32^{\circ} \mathrm{S}$ and ACT, respectively. Calculating the mean transport from 1994 to 2014, and hence for a similar period to the floats and drifters used by Daher et al. (2020), increases the mean Agulhas leakage transport in P only to $10.4 \mathrm{~Sv}$.

A time series of the Agulhas leakage transport for A, $\mathrm{P}$ and P-ACT is shown in Fig. 2b. Here, the transport of the particles that were released in the Agulhas Current each year and then crossed the Good Hope section within 4 years were summed up for each release year. In all Lagrangian experiments, an upward trend in Agulhas leakage is only present between the beginning of the 1960s towards the mid-1980s, but there is no clear trend afterwards. Depending on the exact period within the early 1960 s to mid-1980s the linear trend in Agulhas leakage is between 1 and $2.5 \mathrm{~Sv}$ per decade with the linear trend being calculated for all combinations starting in 1960-1962 and ending in 1982-1983. When considering all years from 1958 to 2014, the linear trend per decade is only $0.5 \mathrm{~Sv}$ in both A and P (Fig. 2b). The lack of a clear upward trend in Agulhas leakage after the 1980s is in contrast to earlier studies using hindcast simulations under the COREv2 forcing. Compared to Agulhas leakage estimates using the same model configuration, but applying the COREv2 forcing (Schwarzkopf et al., 2019), where the linear trend in Agulhas leakage transport from 1965 to 2000 is $1.1 \mathrm{~Sv}$ per decade, the experiments A and P exhibit a weaker trend of only $0.8 \mathrm{~Sv}$ per decade in the same period. This results in a lower mean Agulhas leakage transport for the period 1995-2005 of 10.4 Sv in both A and P compared to the estimate of $12.9 \mathrm{~Sv}$ for INALT20 under COREv2 forcing by Schwarzkopf et al. (2019). In COREv2, the strengthening of the Southern Hemisphere westerlies is stronger compared to JRA55-do (Patara et al., 2021), and a link was suggested between the increase in Agulhas leakage and the changes in Southern Hemisphere westerlies, especially their strengthening (Durgadoo et al., 2013; Biastoch and Böning, 2013; Biastoch et al., 2015; Cheng et al., 2018). Furthermore, first sensitivity studies indicate that the presence of tides in the experiment we analyse here, in contrast to the non-tidal simulation under COREv2 forcing, might contribute to a weaker mean Agulhas leakage. Understanding the details of the impact of Southern Hemisphere westerlies and tides on Agulhas leakage and the differences between Agulhas leakage in INALT20 forced with either JRA55-do or COREv2 is beyond the scope of this and subject to a dedicated study.

If a daily time series of Agulhas leakage is created by summing up the transport of particles that cross the Good Hope section each day, the transport varies considerably on seasonal timescales, which can be attributed to the passage of Agulhas Rings (not shown). The high correlation between $\mathrm{A}$ and $\mathrm{P}$ of these daily time series $(r=0.85, p<0.01)$ furthermore underlines the robustness of our method in terms of specific leakage events with a transport of up to $10 \mathrm{~Sv}$.

The latitude at which particles in the Lagrangian experiments are released in the Agulhas Current changes the mean Agulhas leakage transport, but it has a minor effect on the variability of Agulhas leakage (Cheng et al., 2016). The mean (1958-2014) Agulhas leakage transport in P-ACT, where particles were released along the ACT section at $34^{\circ} \mathrm{S}$ in the Agulhas Current, is $12.2 \mathrm{~Sv}$ and therefore $2.3 \mathrm{~Sv}$ ( $23 \%$ of the Agulhas leakage transport in $\mathrm{P}$ ) higher than in $\mathrm{P}$ with a release further north at $32^{\circ} \mathrm{S}$ (Fig. 2b). This can be partly explained by the increase in the transport of the Agulhas Cur- 
rent between these latitudes due to the increase in Sverdrup transport (Beal et al., 2015). Both time series show a comparable interannual variability with a correlation of $r=0.92$ $(p<0.01)$. A similar comparison of the release location in a climate model also revealed a good correlation between the Agulhas leakage transport time series, but an even stronger increase in the mean Agulhas leakage transport of $2.8 \mathrm{~Sv}$ $(30 \%)$ in the experiment with a release at ACT was found (Cheng et al., 2016). This agrees surprisingly well with our findings given that the atmospheric forcing of the ocean differs due to the intrinsic variability in a climate model leading to a different temporal evolution and variability of Agulhas leakage. The strong nonlinearity of the southern Agulhas Current results in different degrees of recirculation south of $\sim 34^{\circ} \mathrm{S}$, and hence the Agulhas Current transport in different models usually agrees at $32^{\circ} \mathrm{S}$ but disagrees at ACT (Biastoch et al., 2018). The lower Agulhas leakage transport in $\mathrm{P}$ compared to the estimate from observations by Daher et al. (2020) can hence be partly explained by the different reference sections through the Agulhas Current.

\subsection{Transit times from the Indian Ocean into the South Atlantic}

The transit times of waters from the Agulhas Current at $32^{\circ} \mathrm{S}$ to the Good Hope section vary strongly from less than a month up to several years, where a maximum of 4 years is the upper limit due to the design of the experiments (Fig. 3a). The most frequent transit time (modal value of the transit time distribution) is 160 to $170 \mathrm{~d}$ for both $\mathrm{A}$ and $\mathrm{P}$. The majority of transport $(>50 \%)$ reaches the Good Hope section within $280 \mathrm{~d}$ in A and $300 \mathrm{~d}$ in P. More particles with transit times of less than $290 \mathrm{~d}$ are advected towards the Good Hope section in A compared to $\mathrm{P}$, whereas there are more particles in $\mathrm{P}$ with transit times between $290 \mathrm{~d}$ and around 2 years than in A. The faster transit times in A might be due to the different temporal interpolation schemes in Ariane and Parcels (see Sect. 2.2). The transit time required to reach the Good Hope section for the majority of particles has a similar interannual variability and shows no significant trend in both $\mathrm{A}$ and $\mathrm{P}$ (not shown). The distribution of transit times from the Agulhas Current at $32^{\circ} \mathrm{S}$ towards $20^{\circ} \mathrm{E}$ is much narrower and shifted towards shorter timescales (Fig. 3b) because of shorter and more direct pathways, where particles are mostly advected with the Agulhas Current. Therefore, 10 to $20 \mathrm{~d}$ is the most frequent transit time; the majority of transport reaches $20^{\circ} \mathrm{E}$ within $70 \mathrm{~d}$, and within 1 year $92 \%$ of the transport arrives in the Atlantic at $20^{\circ} \mathrm{E}$. In the Agulhas Current the flow is characterized by small differences in velocity and weak recirculation, but once the waters of Agulhas leakage are in the Atlantic, recirculation through interaction with and within the mesoscale in the Cape Basin occurs.

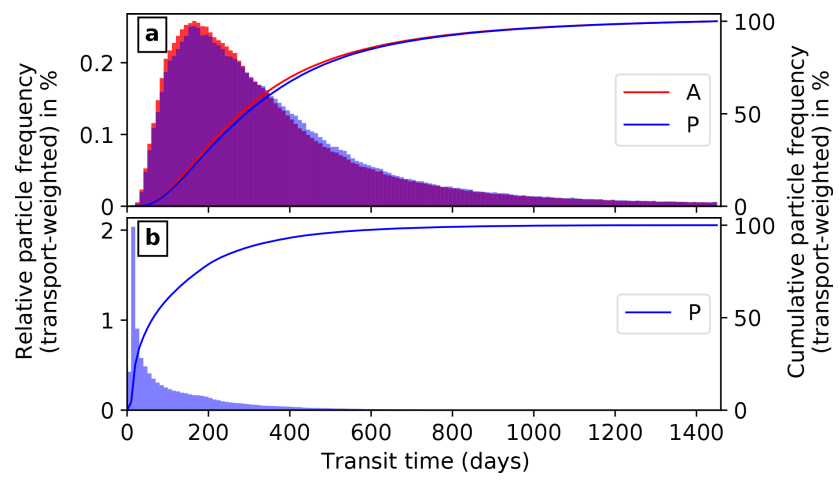

Figure 3. Mean (1958-2014) transit time distribution (transportweighted) of Agulhas leakage from the Agulhas Current at $32^{\circ} \mathrm{S}$ to (a) the Good Hope section and (b) $20^{\circ} \mathrm{E}$ for experiment $\mathrm{A}$ in red and $\mathrm{P}$ in blue, overlapping probabilities are shown in purple. The transit time to $20^{\circ} \mathrm{E}$ can not be analysed in experiment A because it was run in the quantitative mode of Ariane.

\subsection{Robustness of Agulhas leakage estimates to different experimental designs}

Different dates of reference to calculate a time series of the Agulhas leakage transport alter the transport per year, but not the decadal variability and trend of the Agulhas leakage transport. In previous studies, the date of reference of the Agulhas leakage time series has been either the year in which virtual particles were released in the Agulhas Current (e.g. Biastoch et al., 2009; Schwarzkopf et al., 2019) or the date of the last crossing of the Good Hope section (e.g. Loveday et al., 2015; Cheng et al., 2016). An approximation of the Good Hope section has been used in all of these studies as the control section to ensure that waters with an Indian Ocean origin remain in the South Atlantic. The exchange of Indian Ocean and Atlantic water masses occurs already east of the Good Hope section south of the tip of Africa at $20^{\circ} \mathrm{E}$, though. Therefore, the first crossing of $20^{\circ} \mathrm{E}$ is a good reference date for the Agulhas leakage time series as long as it is ensured, by the crossing of the Good Hope section afterwards, that the waters remain in the South Atlantic. Due to the fast transit time from the release section in the Agulhas Current at $32^{\circ} \mathrm{S}$ towards $20^{\circ} \mathrm{E}$ (Fig. 3b), the release year can be used as an approximation of the year of the $20^{\circ} \mathrm{E}$ crossing (Fig. 4a, $r=0.83, p<0.01$ ). For those two time series only the crossing of the Good Hope section was required to be counted as Agulhas leakage. Particles might, however, cross the Good Hope section several times and only particles with an odd number of crossings actually remain in the South Atlantic within the given time period. Applying this additional criterion to the time series referenced to the release year leads to a reduced Agulhas leakage transport by $1 \mathrm{~Sv}$ on average, but with nearly the same interannual variability $(r=0.996$, $p<0.01)$. The transport time series referenced to the release year and the year of the last crossing of the Good Hope sec- 


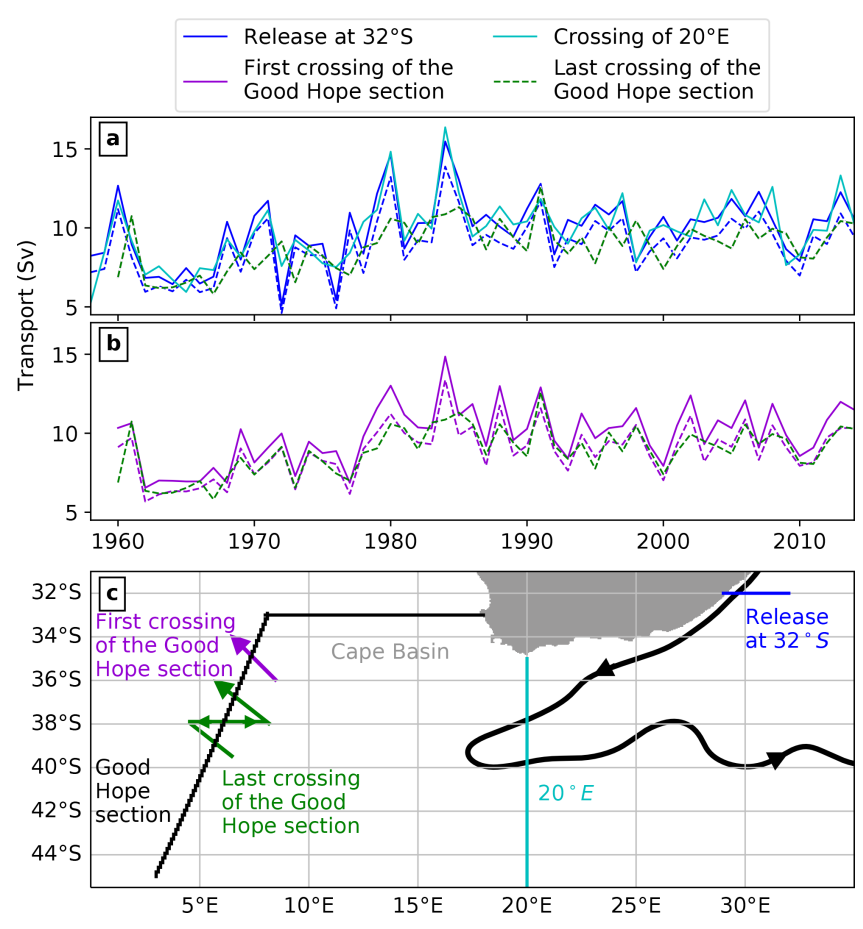

Figure 4. Comparison of the year of reference used to calculate a time series of the Agulhas leakage transport for experiment P: time series of Agulhas leakage transport referenced to the release year (blue in a), year of crossing $20^{\circ} \mathrm{E}$ (cyan in a), year of the first crossing of the Good Hope section (purple in $\mathbf{b}$ ) and year of last crossing of the Good Hope section (green in $\mathbf{a}+\mathbf{b}$ ). Dashed lines show the combined transport of all particles that cross the Good Hope section an odd number of times, while for the solid lines this additional criterion was not applied. (c) Schematic path of the Agulhas Current via the retroflection into the Agulhas Return Current (black arrow) and all the sections used for assigning the reference date in (a) and (b). The Cape Basin is located northwestwards of the Agulhas Retroflection and southeastwards of the Good Hope section.

tion do not correlate well $(r=0.37, p<0.05)$, which is expected due to the transit time. The highest correlation between those time series occurs when the transport time series referenced to the last crossing lags by 1 year $(r=0.76$, $p<0.01$ ). Although the different samplings influence the interannual variability, the decadal variability is not affected and agrees across all time series. Using the date of the Good Hope section crossing as the reference for the Agulhas leakage time series enables to capture crossings of Agulhas Rings for example. There is not a big difference between the Agulhas leakage time series referenced to the first or last crossing of the Good Hope section $(r=0.84, p<0.01)$. Not applying the additional criterion of an odd number of crossings on the time series referenced to the first crossing results again in a higher average transport and only minor changes of the variability.

The date of reference does not have a strong effect on the trend of the Agulhas leakage transport. The trend of the time series is $0.46 \mathrm{~Sv}$ per decade in 1958-2014 when referenced to the last crossing of the Good Hope section as well as when the release year is used as a reference. Due to the potential impact of an increasing leakage under global warming on the AMOC (Beal et al., 2011; Biastoch et al., 2015), the overall trend of the Agulhas leakage transport might be more important than the Agulhas leakage transport in a particular year. As a general rule, we propose to use the year of release as reference for the Agulhas leakage transport time series calculated from the particles crossing the Good Hope section within 4 years. This represents the mean exchange between the Indian and Atlantic Ocean and its temporal changes on decadal timescales towards long-term trends well while keeping the Lagrangian experiment as simple as possible by not introducing another control section at $20^{\circ} \mathrm{E}$. Whether all particles crossing the Good Hope section or only those with an odd number of crossings should be considered depends on the research question. If the advective effect of Agulhas leakage on the overturning circulation is of interest, only particles crossing the Good Hope section an odd number of times and thereby remaining in the South Atlantic shall be referred to as Agulhas leakage. On the other hand, all particles that cross the Good Hope section are important when analysing the effect of Agulhas leakage on the thermohaline properties of water masses in the southeast Atlantic as mixing with water masses from the Atlantic occurs for example already in the Cape Basin (Rimaud et al., 2012; Rusciano et al., 2012), which is so turbulent that particles can either stay there longer than the integration time of the Lagrangian experiment or escape and eventually join the Agulhas Return Current.

\subsection{Thermohaline property modifications of Agulhas leakage waters}

In the following, the thermohaline characteristics of Agulhas leakage are analysed for experiment $\mathrm{P}$ only as we showed that the average transport, its variability and the transit time of Agulhas leakage agree well between experiments A and P. Here, all particles crossing the Good Hope section, regardless of the number of crossings, are analysed.

On its transit into the Atlantic Ocean, an overall cooling and freshening of Agulhas leakage occurs especially at the location of the Agulhas Retroflection, but the modification of thermohaline properties differs between water masses. The $\theta S$ diagram in Fig. 5 reveals that nearly half of the Agulhas leakage transport at both $32^{\circ} \mathrm{S}$ in the Agulhas Current and the Good Hope section consists of central waters with potential density anomalies referenced to the sea surface $\left(\sigma_{0}=\right.$ $\rho_{0}-1000 \mathrm{~kg} \mathrm{~m}^{-3}$; in the following the units are dropped for better readability) of 26 to 26.9. This agrees with in situ observations showing that the core of Agulhas Rings consists of a transformed variety of South Indian Central Waters and Subtropical Mode Waters with $26<\sigma_{0}<26.8$ (Arhan et al., 1999, 2011). During the transit from the Agulhas Cur- 


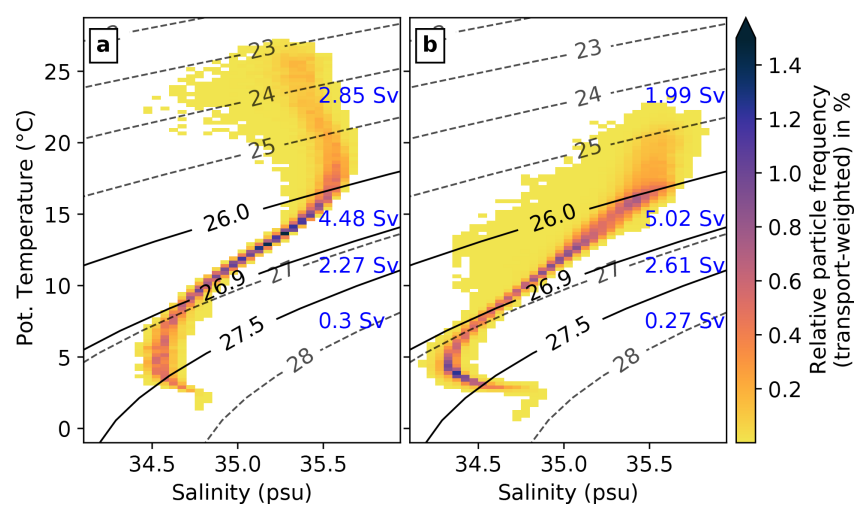

Figure 5. $\theta S$ diagram of Agulhas leakage for experiment $\mathbf{P}$ (a) in the Agulhas Current at $32^{\circ} \mathrm{S}$ and (b) at the first crossing of the Good Hope section. The relative transport-weighted particle frequency is shown per $0.25^{\circ} \mathrm{C} \times 0.05$ psu bin in percent. Potential density levels used to separate upper, central, intermediate and deep waters are highlighted by solid black lines, and blue numbers indicate the transport of these water masses.

rent (Fig. 5a) towards the Good Hope section (Fig. 5b) the amount of upper waters $\left(\sigma_{0}<26\right)$ reduces by 0.9 to $2.0 \mathrm{~Sv}$, equivalent to a reduction of $30 \%$. Thereby, the waters with $\sigma_{0}<25$ are mostly eroded by cooling due to very strong surface heat fluxes in this region (Walker and Mey, 1988). At the same time, the amount of central waters increases by 0.5 to $5.0 \mathrm{~Sv}$ and the amount of AAIW $\left(26.9<\sigma_{0}<27.5\right)$ increases by 0.3 to $2.6 \mathrm{~Sv}$. As more than $95 \%$ of the Agulhas leakage transport is within the upper $1200 \mathrm{~m}$, deep waters denser than $\sigma_{0}=27.5$ constitute a negligible amount of Agulhas leakage in agreement with observations (Gordon et al., 1987). This confirms the assumption by Richardson (2007) and Daher et al. (2020) that available floats drifting at $1000 \mathrm{~m}$ represent Agulhas leakage over the full depth well.

The modifications of temperature and salinity and their effect on density are shown in more detail in Figs. 6 and 7 for each water mass. The upper waters and the AAIW cool continuously during the transit, while the temperature distribution of the central waters broadens especially between $32^{\circ} \mathrm{S}$ and $20^{\circ} \mathrm{E}$ (Fig. 6a, d, g). The horizontal distribution of density changes due to the thermal effect in the left column of Fig. 7 confirms the cooling of all water masses, leading to a density gain, which occurs in most of the area south of Africa. The upper waters experience the strongest density gain due to cooling, which occurs in the Agulhas Current and the southern part of the Cape Basin within the Agulhas Ring corridor (see Fig. 4c for the location of the Cape Basin). A density loss takes place in the northern part of the Cape Basin, but of smaller magnitude compared to the gain. The area of the strongest density changes due to the thermal effect is within the major pathway of Agulhas leakage around South Africa following the Agulhas Current and the Agulhas Ring corridor (Fig. 7a). The density changes of the central waters and the AAIW have a similar pattern, but they have a smaller magnitude for the AAIW, with a density decrease due to warming along the coast of South Africa and a density increase in particular around the Agulhas Retroflection. The mean depth of the $\sigma_{0}=26$ surface, which is the upper boundary of the central waters, suggests that different dynamical processes are responsible for the density changes of the central waters south of Africa. In the Agulhas Current and Agulhas Retroflection region central waters are mostly found below at least $100 \mathrm{~m}$, which is below the mean winter mixed layer depth (indicated by the cyan line in Fig. 7f), suggesting a change in density mainly due to mixing with other water masses. To the northwest, in particular in the Cape Basin, the depth of the central waters shallows to a minimum depth of 50-100 m, which is within the mean winter mixed layer, and therefore air-sea fluxes might modify the thermohaline properties of the shallower central waters. The modifications of the salinity has a smaller effect on the density compared to the thermal effect but is not negligible especially for the intermediate waters. There is a salinification and hence density gain of the upper waters all around South Africa with freshening only in the southern part of the Cape Basin (Fig. 7e). This is in agreement with a slight shift towards higher salinities between the release and $20^{\circ} \mathrm{E}$ and a decrease afterwards in Fig. 6b. The central waters and the AAIW experience a freshening, which dominates in the region and partly cancels out the thermal effect on the density. The freshening of AAIW is a result of mixing with AAIW from the Atlantic in the Cape Basin (Rimaud et al., 2012; Rusciano et al., 2012). The changes in density of all water masses of Agulhas leakage combined shows that cooling in the Cape Basin has the strongest impact on the density (Fig. 7b). Initially Agulhas leakage waters are relatively warm and saline, which is a density-compensated anomaly. As they lose their thermal signature during the transit, a positive density anomaly due to the anomalously high salinity spreads north into the South Atlantic (Weijer et al., 2002; Biastoch et al., 2009).

\section{Conclusions}

In this study, we assessed the robustness of Agulhas leakage estimates as well as the thermohaline property modifications of Agulhas leakage between the Agulhas Current and the Cape Basin in the eddy-rich ocean-sea-ice model INALT20 $\left(1 / 20^{\circ}\right.$ horizontal resolution). We performed Lagrangian experiments to estimate Agulhas leakage, validate the results by the Lagrangian tool Parcels against the one by the well established tool Ariane and analyse the effect that different designs of the Lagrangian experiments have on the simulated transport. In these experiments, particles were released in the Agulhas Current and all particles crossing the Good Hope section in the Cape Basin were referred to as Agulhas leakage. The regions of the strongest modifications of the thermohaline properties during this transit were identified. 


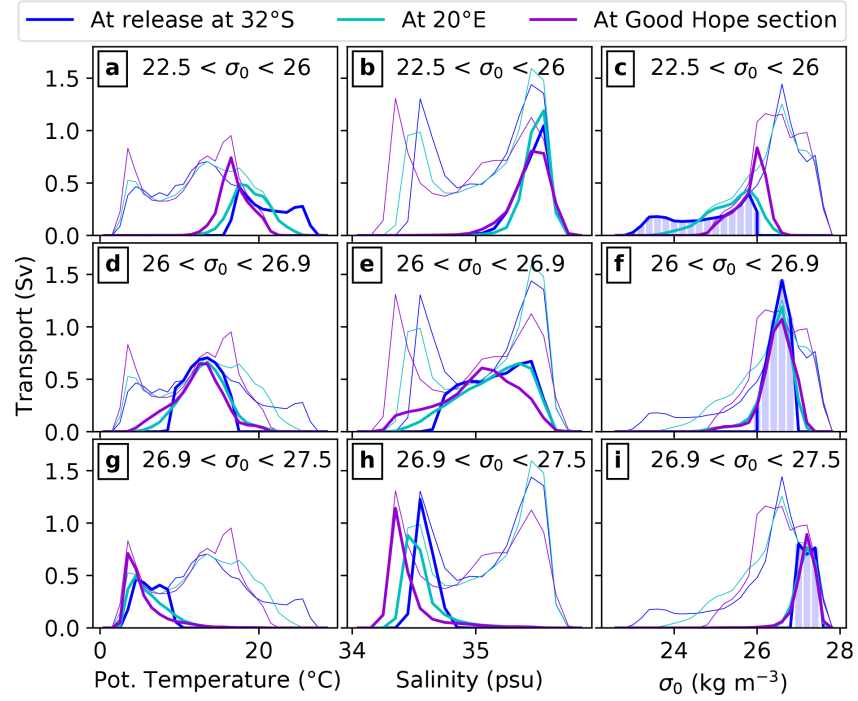

Figure 6. Thermohaline property modification of Agulhas leakage waters for experiment P: transport of $(\mathbf{a}-\mathbf{c})$ upper waters $(22.5<$ $\left.\sigma_{0}<26\right)$, (d-f) central waters $\left(26<\sigma_{0}<26.9\right)$ and (g-i) AAIW $\left(26.9<\sigma_{0}<27.5\right)$ per potential temperature (a, d, $\mathbf{g}, 1^{\circ} \mathrm{C}$ bins $)$, salinity (b, e, h, 0.1 psu bins) and $\sigma_{0}\left(\mathbf{c}, \mathbf{f}, \mathbf{i}, 0.2 \mathrm{~kg} \mathrm{~m}^{-3}\right.$ bins) class. To assign waters to these water masses, $\sigma_{0}$ in the Agulhas Current at $32^{\circ} \mathrm{S}$ is used, highlighted by the blue shading. The properties at the release at $32^{\circ} \mathrm{S}$ are shown as blue, at $20^{\circ} \mathrm{E}$ as cyan and at the first crossing of the Good Hope section as purple lines. The thin lines show the transport of all water masses together including the deep waters $\left(\sigma_{0}>27.5\right)$.

The mean (1958-2014) transport of Agulhas leakage and the Agulhas Return Current and their variability as well as the transit times and trend of Agulhas leakage agree in the experiments with Parcels and Ariane. We estimated a mean (1958-2014) Agulhas leakage transport of $9.7 \mathrm{~Sv}$ with Ariane and $9.9 \mathrm{~Sv}$ with Parcels. The transit time of Agulhas leakage from the Agulhas Current at $32^{\circ} \mathrm{S}$ to the Good Hope section varies between less than a month to several years with the most frequent transit time of half a year. Agulhas leakage increases from the early 1960s to mid-1980s by 1 to $2.5 \mathrm{~Sv}$ per decade depending on the exact period for the calculations, but we find no clear trend afterwards under the JRA55-do forcing, which is in contrast to previous studies using hindcast simulations under the COREv2 forcing. The causes of the different trends need further investigations, but an explanation might be the more pronounced strengthening of the Southern Hemisphere westerlies in COREv2 compared to JRA55-do (Patara et al., 2021) as an increase in Agulhas leakage is linked to the changes in Southern Hemisphere westerlies, especially their strengthening (Durgadoo et al., 2013; Biastoch and Böning, 2013; Biastoch et al., 2015; Cheng et al., 2018).

The effect of different designs of the Lagrangian experiment on the Agulhas leakage transport is more pronounced than that found when using the two different Lagrangian

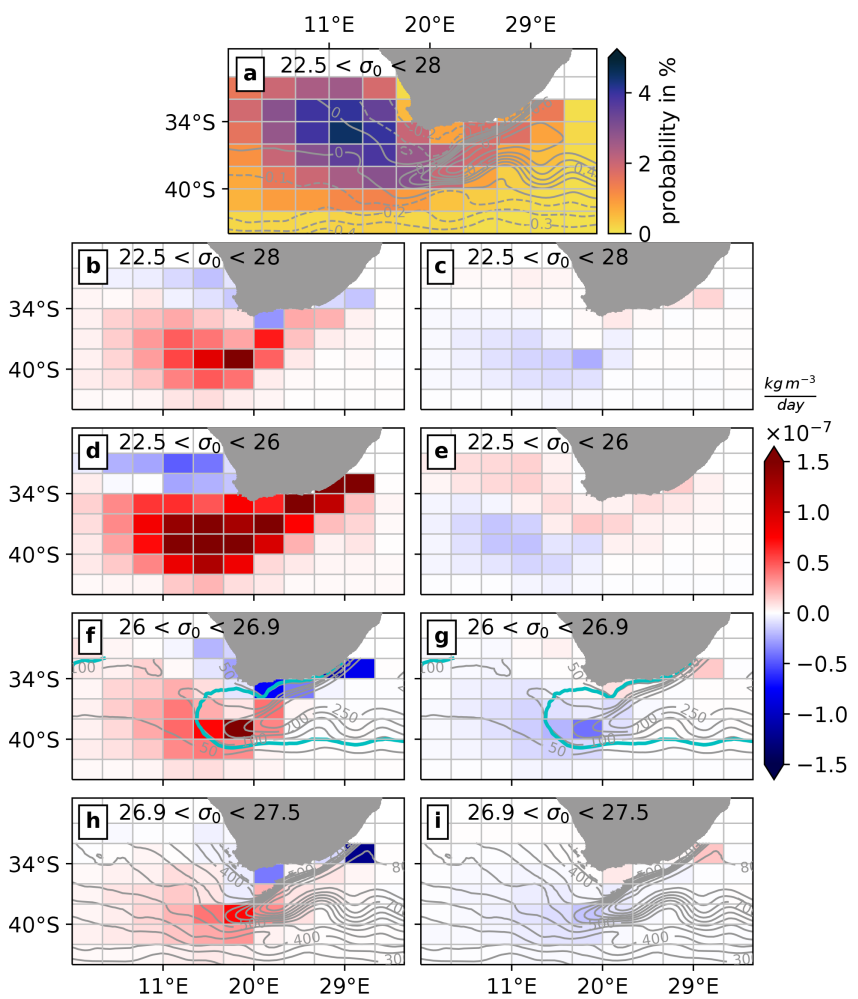

Figure 7. Pathways and horizontal distribution of the density changes of Agulhas leakage for experiment P: (a) relative transportweighted probability in percent of all Agulhas leakage waters (considering all Agulhas leakage particles per bin at each time step). Contour lines show the mean (1958-2014) sea surface height (in m). Density changes due to the (b, d, f, h) thermal and (c, e, g, i) haline effect for $(\mathbf{b}, \mathbf{c})$ all water masses, $(\mathbf{d}, \mathbf{e})$ upper waters $\left(22.5<\sigma_{0}<26\right)$, (f, g) central waters $\left(26<\sigma_{0}<26.9\right)$ and (h, i) AAIW $\left(26.9<\sigma_{0}<27.5\right)$. To assign waters to these water masses, $\sigma_{0}$ in the Agulhas Current at $32^{\circ} \mathrm{S}$ is used. The bin size of all histograms is $2^{\circ}$ in latitude $\times 3^{\circ}$ in longitude. See Sect. 2.3 for details on the calculation. Grey contour lines in $(\mathbf{f}, \mathbf{g})$ and $(\mathbf{h}, \mathbf{i})$ show the mean (1958-2014) depth of the $\sigma_{0}=26$ and $\sigma_{0}=26.9$ surfaces, respectively. East of the cyan line the mean (1958-2014) depth of $\sigma_{0}=26$ is below the mean (1958-2014) winter (JJA) mixed layer depth.

tools Parcels and Ariane. Shifting the release section in the Agulhas Current further south to the ACT section at $34^{\circ} \mathrm{S}$ increases the mean transport of Agulhas leakage by 2.3 to 12.2 Sv, but the interannual variability is comparable. Calculating the Agulhas leakage transport only from particles that cross the Good Hope section an odd number of times results in a decrease by $1 \mathrm{~Sv}$. Different dates of reference to calculate a time series of the Agulhas leakage transport alter the transport per year, but not the decadal variability and trend of it. This, in combination with the fast transit time of the majority of Agulhas leakage waters of less than a year from the Agulhas Current at $32^{\circ} \mathrm{S}$ to the Good Hope section, supports the use of the release year as the reference time for the Agulhas 
leakage transport. All of these test cases show that changing certain parameters of the Lagrangian experiment can affect in particular the total transport of Agulhas leakage, even if the same Lagrangian tool is being used, and that designing such an experiment to estimate Agulhas leakage is not straightforward due to the turbulent regime. Comparing the total transport of studies with different ocean models, observational products and techniques to estimate Agulhas leakage needs to be done with caution, while transport anomalies and trends are assumed to be more robust across different estimates if the same atmospheric conditions prevail. Furthermore, the horizontal resolution of the ocean model employed here is not sufficient to resolve submesoscale dynamics. Increasing the horizontal resolution to $1 / 60^{\circ}$ in the INALT model family and thereby resolving submesoscale flows improves the representation of mesoscale eddies in the Agulhas Ring corridor (Schubert et al., 2019, 2020). In particular the representation of lee cyclones west of the Agulhas bank improves when submesoscale flows are resolved (Schubert et al., 2021). The lee cyclones are important for the formation of Agulhas filaments, which contribute to $40 \%$ more Agulhas leakage, when the resolution is increased to $1 / 60^{\circ}$ (Schubert et al., 2021). The absence of submesoscale flows thus can partly explain the overly low Agulhas leakage transport in INALT20 compared to observations. Submesoscale dynamics also influence the mode and intermediate water properties by the formation of mode waters in Agulhas Rings, which only occurs if the submesoscale is resolved, and the AAIW transformation in its regional varieties (Capuano et al., 2018).

In terms of thermohaline properties, we showed that they are modified not only in the Cape Basin, but also in other regions of the Agulhas Current system. Agulhas leakage consists of upper and intermediate waters with nearly half of $\mathrm{Ag}$ ulhas leakage being central waters at both $32^{\circ} \mathrm{S}$ in the $\mathrm{Ag}$ ulhas Current and the Good Hope section. During the transit from the Agulhas Current at $32^{\circ} \mathrm{S}$ to the Cape Basin the amount of upper waters decreases, whereas the amount of central waters and AAIW increases. The water property modification during the transit is due to a cooling and freshening of Agulhas leakage waters, which occurs especially at the location of the Agulhas Retroflection. This leads to a density increase as the thermal effect dominates. The upper waters experience the strongest changes in density, especially due to a cooling through heat loss in the Agulhas Current and the Agulhas Ring corridor in the southern part of the Cape Basin. The freshening is more pronounced in the central waters and AAIW, while in the upper waters the salinification and freshening in different regions compensate each other. The impact of Agulhas leakage and its temporal changes can not only be interpreted based on the transport, but also the thermohaline properties of Agulhas waters and their spatial and temporal changes need to be taken into account. A substantial increase in total heat and salt fluxes across the Good Hope section over the last decades is the result of a combined effect of changes in transport and water mass properties of
Agulhas leakage (Loveday et al., 2015; Rouault et al., 2009; Biastoch et al., 2015).

We have confirmed that estimating Agulhas leakage with the Lagrangian tool Parcels leads to very similar results to simulations with Ariane. Even though the numerical integration scheme of Parcels is not volume conserving by definition like the analytical method in Ariane, our results show that Parcels can be used for volume transport estimations. Using the fourth-order Runge-Kutta scheme with Parcels results, however, in longer computing times compared to the experiment with Ariane, but the Parcels team is working on an analytical method and increased efficiency and aims for a parallel version (Delandmeter and van Sebille, 2019). This opens up new opportunities for future studies due to the flexibility of Parcels. Agulhas leakage could also be estimated with Parcels based on a variety of differently gridded products, e.g. reanalysis products, which do not have a non-divergent velocity field as required by Ariane. Velocity fields of an ocean model with a non-linear free surface can also not be used in Ariane. Another useful feature of Parcels is the ability to build a realistic, global velocity field consisting of model output with different resolutions for different domains. In the case of INALT20, particles would be advected with velocities from the nest with its mesoscale-resolving horizontal resolution of $1 / 20^{\circ}$ in the Agulhas Current system and velocities from the global host $\left(1 / 4^{\circ}\right.$ horizontal resolution) everywhere else. Such an experimental design can be used to for example analyse the far-field impact of Agulhas leakage on the AMOC.

Code and data availability. The Lagrangian software Parcels is available at http://oceanparcels.org/ (OceanParcels project, 2021) and Ariane at http://mespages.univ-brest.fr/ grima/Ariane/ (Laboratoire d'Océanographie Physique et Spatiale, 2021). For reproducibility of all results, the scripts to perform the Lagrangian experiments and the postprocessing scripts as well as all data required to produce the figures are made available through GEOMAR (https://hdl.handle.net/20.500.12085/ b704e917-09dd-4a73-b6a1-ea24a549920c, Schmidt et al., 2021).

Author contributions. AB, SR and CS defined the overall research problem and methodology. FUS developed, ran and validated the ocean model simulation and performed the Lagrangian experiments with Ariane. CS performed the Lagrangian experiments with Parcels, analysed all Lagrangian simulations, produced all figures and prepared the paper. All co-authors discussed the analyses and contributed to the text.

Competing interests. The authors declare that they have no conflict of interest. 
Disclaimer. Publisher's note: Copernicus Publications remains neutral with regard to jurisdictional claims in published maps and institutional affiliations.

Acknowledgements. The ocean model simulation was performed at the North German Supercomputing Alliance (HLRN) and on the ESM partition at Jülich supercomputing centre (JUWELS); the trajectory simulations were conducted at the Christian-AlbrechtsUniversität zu Kiel (NESH). We thank the Ariane and Parcels teams for support. We thank René Schubert for helpful discussions, Willi Rath and Katharina Höflich for technical support, and two anonymous reviewers for their useful comments which improved the paper.

Financial support. This research has been supported by the German Federal Ministry of Education and Research (grant no. SPACES-CASISAC (03F0796A)). It has also received funding from the Initiative and Networking Fund of the Helmholtz Association through the project "Advanced Earth System Modelling Capacity (ESM)".

The article processing charges for this open-access publication were covered by the GEOMAR Helmholtz Centre for Ocean Research Kiel.

Review statement. This paper was edited by Katsuro Katsumata and reviewed by two anonymous referees.

\section{References}

Ansorge, I. J., Speich, S., Lutjeharms, J. R., Göni, G. J., Rautenbach, C. J., Froneman, P. W., Rouault, M., and Garzoli, S.: Monitoring the oceanic flow between Africa and Antarctica: Report of the first GoodHope cruise, S. Afr. J. Sci., 101, 29-35, 2005.

Arhan, M., Mercier, H., and Lutjeharms, J. R.: The disparate evolution of three Agulhas rings in the South Atlantic Ocean, J. Geophys. Res.-Oceans, 104, 20987-21005, https://doi.org/10.1029/1998jc900047, 1999.

Arhan, M., Speich, S., Messager, C., Dencausse, G., Fine, R., and Boye, M.: Anticyclonic and cyclonic eddies of subtropical origin in the subantarctic zone south of Africa, J. Geophys. Res.-Oceans, 116, 1-22, https://doi.org/10.1029/2011JC007140, 2011.

Backeberg, B. C., Penven, P., and Rouault, M.: Impact of intensified Indian Ocean winds on mesoscale variability in the Agulhas system, Nat. Clim. Change, 2, 608-612, https://doi.org/10.1038/nclimate1587, 2012.

Beal, L. M., De Ruijter, W. P., Biastoch, A., Zahn, R., Cronin, M., Hermes, J., Lutjeharms, J., Quartly, G., Tozuka, T., Baker-Yeboah, S., Bornman, T., Cipollini, P., Dijkstra, H., Hall, I., Park, W., Peeters, F., Penven, P., Ridderinkhof, H., and Zinke, J.: On the role of the Agulhas system in ocean circulation and climate, Nature, 472, 429-436, https://doi.org/10.1038/nature09983, 2011.
Beal, L. M., Elipot, S., Houk, A., and Leber, G. M.: Capturing the Transport Variability of a Western Boundary Jet: Results from the Agulhas Current Time-Series Experiment (ACT)*, J. Phys. Oceanogr., 45, 1302-1324, https://doi.org/10.1175/jpo-d14-0119.1, 2015.

Biastoch, A. and Böning, C. W.: Anthropogenic impact on Agulhas leakage, Geophys. Res. Lett., 40, 1138-1143, https://doi.org/10.1002/grl.50243, 2013.

Biastoch, A., Lutjeharms, J. R., Böning, C. W., and Scheinert, M.: Mesoscale perturbations control inter-ocean exchange south of Africa, Geophys. Res. Lett., 35, 2000-2005, https://doi.org/10.1029/2008GL035132, 2008.

Biastoch, A., Böning, C. W., Schwarzkopf, F. U., and Lutjeharms, J. R.: Increase in Agulhas leakage due to poleward shift of Southern Hemisphere westerlies, Nature, 462, 495-498, https://doi.org/10.1038/nature08519, 2009.

Biastoch, A., Durgadoo, J. V., Morrison, A. K., van Sebille, E., Weijer, W., and Griffies, S. M.: Atlantic multi-decadal oscillation covaries with Agulhas leakage, Nature Commun., 6, 10082, https://doi.org/10.1038/ncomms10082, 2015.

Biastoch, A., Sein, D., Durgadoo, J. V., Wang, Q., and Danilov, S.: Simulating the Agulhas system in global ocean models - nesting vs. multi-resolution unstructured meshes, Ocean Modell., 121, 117-131, https://doi.org/10.1016/j.ocemod.2017.12.002, 2018.

Blanke, B. and Raynaud, S.: Kinematics of the Pacific Equatorial Undercurrent: An Eulerian and Lagrangian approach from GCM results, J. Phys. Oceanogr., 27, 1038-1053, https://doi.org/10.1175/15200485(1997)027<1038:KOTPEU>2.0.CO;2, 1997.

Blanke, B., Arhan, M., Madec, G., and Roche, S.: Warm water paths in the equatorial Atlantic as diagnosed with a general circulation model, J. Phys. Oceanogr., 29, 2753-2768, https://doi.org/10.1175/15200485(1999)029<2753:WWPITE>2.0.CO;2, 1999.

Boebel, O., Lutjeharms, J., Schmid, C., Zenk, W., Rossby, T., and Barron, C.: The Cape Cauldron: A regime of turbulent inter-ocean exchange, Deep Sea Res. II, 50, 57-86, https://doi.org/10.1016/S0967-0645(02)00379-X, 2003.

Capuano, T. A., Speich, S., Carton, X., and Blanke, B.: Mesoscale and Submesoscale Processes in the Southeast Atlantic and Their Impact on the Regional Thermohaline Structure, J. Geophys. Res.-Oceans, 123, 1937-1961, https://doi.org/10.1002/2017JC013396, 2018.

Cheng, Y., Putrasahan, D., Beal, L., and Kirtman, B.: Quantifying Agulhas leakage in a high-resolution climate model, J. Clim., 29, 6881-6892, https://doi.org/10.1175/JCLI-D-15-0568.1, 2016.

Cheng, Y., Beal, L. M., Kirtman, B. P., and Putrasahan, D.: Interannual Agulhas leakage variability and its regional climate imprints, J. Clim., 31, 10105-10121, https://doi.org/10.1175/JCLID-17-0647.1, 2018.

Daher, H., Beal, L. M., and Schwarzkopf, F. U.: A new improved estimation of Agulhas Leakage using observations and simulations of Lagrangian floats and drifters, J. Geophys. Res.-Oceans, 125, e2019JC015753, https://doi.org/10.1029/2019JC015753, 2020.

de Ruijter, W. P. M., Biastoch, A., Drijfhout, S. S., Lutjeharms, J. R. E., Matano, R. P., Pichevin, T., van Leeuwen, P. J., and Weijer, W.: Indian-Atlantic interocean exchange: Dynamics, estimation and impact, J. Geophys. Res.-Oceans, 104, 20885-20910, https://doi.org/10.1029/1998jc900099, 1999. 
Debreu, L., Vouland, C., and Blayo, E.: AGRIF: Adaptive grid refinement in Fortran, Comput. Geosci., 34, 8-13, https://doi.org/10.1016/j.cageo.2007.01.009, 2008.

Delandmeter, P. and van Sebille, E.: The Parcels v2.0 Lagrangian framework: new field interpolation schemes, Geosci. Model Dev., 12, 3571-3584, https://doi.org/10.5194/gmd-123571-2019, 2019.

Doglioli, A. M., Veneziani, M., Blanke, B., Speich, S., and Griffa, A.: A Lagrangian analysis of the Indian-Atlantic interocean exchange in a regional model, Geophys. Res. Lett., 33, 1-5, https://doi.org/10.1029/2006GL026498, 2006.

Donners, J. and Drijfhout, S. S.: The Lagrangian view of South Atlantic interocean exchange in a global ocean model compared with inverse model results, J. Phys. Oceanogr., 34, 1019-1035, https://doi.org/10.1175/15200485(2004)034<1019:TLVOSA>2.0.CO;2, 2004.

Durgadoo, J. V., Loveday, B. R., Reason, C. J., Penven, P., and Biastoch, A.: Agulhas leakage predominantly responds to the southern hemisphere westerlies, J. Phys. Oceanogr., 43, 2113-2131, https://doi.org/10.1175/JPO-D-13-047.1, 2013.

Fichefet, T. and Maqueda, M. A.: Sensitivity of a global sea ice model to the treatment of ice thermodynamics and dynamics, J. Geophys. Res.-Oceans, 102, 12609-12646, https://doi.org/10.1029/97JC00480, 1997.

Gordon, A. L., Lutjeharms, J. R., and Gründlingh, M. L.: Stratification and circulation at the Agulhas Retroflection, Deep Sea Res. A, 34, 565-599, https://doi.org/10.1016/0198-0149(87)90006-9, 1987.

Lange, M. and van Sebille, E.: Parcels v0.9: prototyping a Lagrangian ocean analysis framework for the petascale age, Geosci. Model Dev., 10, 4175-4186, https://doi.org/10.5194/gmd-104175-2017, 2017.

Large, W. G. and Yeager, S. G.: The global climatology of an interannually varying air - Sea flux data set, Clim. Dynam., 33, 341-364, https://doi.org/10.1007/s00382-008-0441-3, 2009.

Le Bars, D., Durgadoo, J. V., Dijkstra, H. A., Biastoch, A., and De Ruijter, W. P. M.: An observed 20-year time series of Agulhas leakage, Ocean Sci., 10, 601-609, https://doi.org/10.5194/os-10601-2014, 2014.

Laboratoire d'Océanographie Physique et Spatiale (LOPS): Ariane, available at: http://mespages.univ-brest.fr/ grima/Ariane/, last access: 10 August 2021.

Loveday, B. R., Penven, P., and Reason, C. J.: Southern Annular Mode and westerly-wind-driven changes in Indian-Atlantic exchange mechanisms, Geophys. Res. Lett., 42, 4912-4921, https://doi.org/10.1002/2015GL064256, 2015.

Lutjeharms, J. R.: The Agulhas Current, Springer, Berlin, ISBN 978-3-540-37212-7, 2006.

Madec, G. and the NEMO Team: NEMO ocean engine - version 3.6, Note du Pôle de modélisation, Institut Pierre-Simon Laplace, 27, 2014.

OceanParcels project: http://oceanparcels.org/, last access: $10 \mathrm{Au}-$ gust 2021.

Paris, C. B., Helgers, J., van Sebille, E., and Srinivasan, A.: Connectivity Modeling System: A probabilistic modeling tool for the multi-scale tracking of biotic and abiotic variability in the ocean, Environ. Model. Soft., 42, 47-54, https://doi.org/10.1016/j.envsoft.2012.12.006, 2013.
Patara, L., Böning, C. W., and Tanhua, T.: Multidecadal Changes in Southern Ocean Ventilation since the 1960s Driven by Wind and Buoyancy Forcing, J. Clim., 34, 1485-1502, https://doi.org/10.1175/jcli-d-19-0947.1, 2021.

Putrasahan, D. A., Beal, L. M., Kirtman, B. P., and Cheng, Y.: A new Eulerian method to estimate "spicy" Agulhas leakage in climate models, Geophys. Res. Lett., 42, 4532-4539, https://doi.org/10.1002/2015GL064482, 2015.

Qin, X., van Sebille, E., and Sen Gupta, A.: Quantification of errors induced by temporal resolution on Lagrangian particles in an eddy-resolving model, Ocean Model., 76, 20-30, https://doi.org/10.1016/j.ocemod.2014.02.002, 2014.

Richardson, P. L.: Agulhas leakage into the Atlantic estimated with subsurface floats and surface drifters, Deep-Sea Res. I, 54, 13611389, https://doi.org/10.1016/j.dsr.2007.04.010, 2007.

Rimaud, J., Speich, S., Blanke, B., and Grima, N.: The exchange of Intermediate Water in the southeast Atlantic: Water mass transformations diagnosed from the Lagrangian analysis of a regional ocean model, J. Geophys. Res.-Oceans, 117, 1-21, https://doi.org/10.1029/2012JC008059, 2012.

Rouault, M., Penven, P., and Pohl, B.: Warming in the Agulhas Current system since the 1980's, Geophys. Res. Lett., 36, 2-6, https://doi.org/10.1029/2009GL037987, 2009.

Rühs, S., Schwarzkopf, F. U., Speich, S., and Biastoch, A.: Cold vs. warm water route - sources for the upper limb of the Atlantic Meridional Overturning Circulation revisited in a high-resolution ocean model, Ocean Sci., 15, 489-512, https://doi.org/10.5194/os-15-489-2019, 2019.

Rusciano, E., Speich, S., and Ollitrault, M.: Interocean exchanges and the spreading of Antarctic Intermediate Water south of Africa, J. Geophys. Res.-Oceans, 117, 1-21, https://doi.org/10.1029/2012JC008266, 2012.

Schmid, C., Boebel, O., Zenk, W., Lutjeharms, J. R., Garzoli, S. L., Richardson, P. L., and Barron, C.: Early evolution of an Agulhas Ring, Deep-Sea Res. II, 50, 141-166, https://doi.org/10.1016/S0967-0645(02)00382-X, 2003.

Schmidt, C., Schwarzkopf, F. U., Rühs, S., and Biastoch, A.: Supplementary Data to "Characteristics and robustness of Agulhas leakage estimates: an inter-comparison study of Lagrangian methods", GEOMAR [code and data set], available at: https://hdl.handle.net/20.500.12085/ b704e917-09dd-4a73-b6a1-ea24a549920c, 2021.

Schubert, R., Schwarzkopf, F. U., Baschek, B., and Biastoch, A.: Submesoscale Impacts on Mesoscale Agulhas Dynamics, J. Adv. Model. Earth Syst., 11, 2745-2767, https://doi.org/10.1029/2019MS001724, 2019.

Schubert, R., Gula, J., Greatbatch, R. J., Baschek, B., and Biastoch, A.: The submesoscale kinetic energy cascade: Mesoscale absorption of submesoscale mixed layer eddies and frontal downscale fluxes, J. Phys. Oceanogr., 50, 2573-2589, https://doi.org/10.1175/JPO-D-19-0311.1, 2020.

Schubert, R., Gula, J., and Biastoch, A.: Submesoscale Flows Impact Agulhas Leakage, Nature Commun., in review, 2021.

Schwarzkopf, F. U., Biastoch, A., Böning, C. W., Chanut, J., Durgadoo, J. V., Getzlaff, K., Harlaß, J., Rieck, J. K., Roth, C., Scheinert, M. M., and Schubert, R.: The INALT family - a set of high-resolution nests for the Agulhas Current system within global NEMO ocean/sea-ice configurations, Geosci. 
Model Dev., 12, 3329-3355, https://doi.org/10.5194/gmd-123329-2019, 2019.

Shchepetkin, A. F. and McWilliams, J. C.: A method for computing horizontal pressure-gradient force in an oceanic model with a nonaligned vertical coordinate, J. Geophys. Res.-Oceans, 108, 1-34, https://doi.org/10.1029/2001jc001047, 2003.

Speich, S., Lutjeharms, J. R., Penven, P., and Blanke, B.: Role of bathymetry in Agulhas Current configuration and behaviour, Geophys. Res. Lett., 33, 2-6, https://doi.org/10.1029/2006GL027157, 2006.

Tsujino, H., Urakawa, S., Nakano, H., Small, R. J., Kim, W. M., Yeager, S. G., Danabasoglu, G., Suzuki, T., Bamber, J. L., Bentsen, M., Böning, C. W., Bozec, A., Chassignet, E. P., Curchitser, E., Boeira Dias, F., Durack, P. J., Griffies, S. M., Harada, Y., Ilicak, M., Josey, S. A., Kobayashi, C., Kobayashi, S., Komuro, Y., Large, W. G., Le Sommer, J., Marsland, S. J., Masina, S., Scheinert, M., Tomita, H., Valdivieso, M., and Yamazaki, D.: JRA-55 based surface dataset for driving ocean-sea-ice models (JRA55-do), Ocean Model., 130, 79-139, https://doi.org/10.1016/j.ocemod.2018.07.002, 2018.

van Sebille, E., Barron, C. N., Biastoch, A., van Leeuwen, P. J., Vossepoel, F. C., and de Ruijter, W. P. M.: Relating Agulhas leakage to the Agulhas Current retroflection location, Ocean Sci., 5, 511-521, https://doi.org/10.5194/os-5-511-2009, 2009.

van Sebille, E., van Leeuwen, P. J., Biastoch, A., and de Ruijter, W. P.: Flux comparison of Eulerian and Lagrangian estimates of Agulhas leakage: A case study using a numerical model, Deep-Sea Res. I, 57, 319-327, https://doi.org/10.1016/j.dsr.2009.12.006, 2010.

van Sebille, E., England, M. H., Zika, J. D., and Sloyan, B. M.: Tasman leakage in a fine-resolution ocean model, Geophys. Res. Lett., 39, 2-6, https://doi.org/10.1029/2012GL051004, 2012. van Sebille, E., Sprintall, J., Schwarzkopf, F. U., Sen Gupta, A., Santoso, A., England, M. H., Biastoch, A., and Böning, C. W.: Pacific-to-Indian Ocean connectivity: Tasman leakage, Indonesian Throughflow, and the role of ENSO, J. Geophys. Res.Oceans, 129, 1365-1382, https://doi.org/10.1038/175238c0, 2014.

van Sebille, E., Griffies, S. M., Abernathey, R., Adams, T. P., Berloff, P., Biastoch, A., Blanke, B., Chassignet, E. P., Cheng, Y., Cotter, C. J., Deleersnijder, E., Döös, K., Drake, H. F., Drijfhout, S., Gary, S. F., Heemink, A. W., Kjellsson, J., Koszalka, I. M., Lange, M., Lique, C., MacGilchrist, G. A., Marsh, R., Mayorga Adame, C. G., McAdam, R., Nencioli, F., Paris, C. B., Piggott, M. D., Polton, J. A., Rühs, S., Shah, S. H., Thomas, M. D., Wang, J., Wolfram, P. J., Zanna, L., and Zika, J. D.: Lagrangian ocean analysis: Fundamentals and practices, Ocean Model., 121, 4975, https://doi.org/10.1016/j.ocemod.2017.11.008, 2018.

Walker, N. D. and Mey, R. D.: Ocean/atmosphere heat fluxes within the Agulhas Retroflection region, J. Geophys. Res., 93, 1547315483, 1988.

Weijer, W. and van Sebille, E.: Impact of Agulhas leakage on the Atlantic overturning circulation in the CCSM4, J. Clim., 27, 101110, https://doi.org/10.1175/JCLI-D-12-00714.1, 2014.

Weijer, W., de Ruijter, W. P., Sterl, A., and Drijfhout, S. S.: Response of the Atlantic overturning circulation to South Atlantic sources of buoyancy, Global Planet.Change, 34, 293-311, https://doi.org/10.1016/S0921-8181(02)00121-2, 2002. 